\title{
Presbyopia Treatments by Mechanism of Action: A New Classification System Based on a Review of the Literature
}

\author{
Daniel H Chang' \\ George O Waring $4 \mathrm{th}^{2}$ \\ Milton $\mathrm{Hom}^{3}$ \\ Melissa Barnett $\mathbb{D}^{4}$ \\ 'Empire Eye and Laser Center, \\ Bakersfield, CA, USA; ${ }^{2}$ Waring Vision \\ Institute, Mt. Pleasant, SC, USA; ${ }^{3}$ Canyon \\ City Eyecare, Azusa, CA, USA; \\ ${ }^{4}$ University of California, Davis Eye \\ Center, Sacramento, CA, USA
}

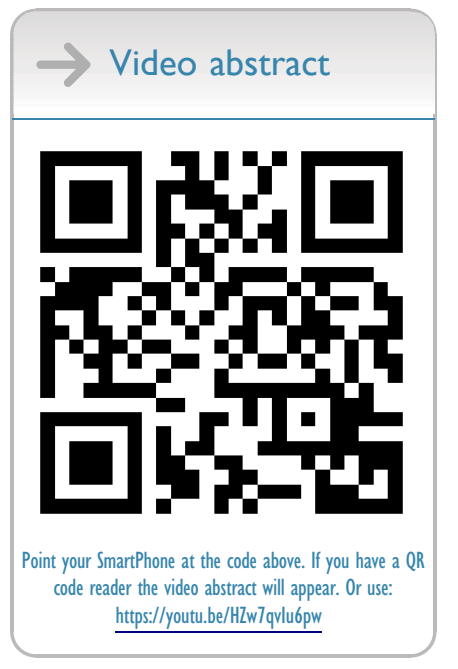

Correspondence: Daniel H Chang Empire Eye and Laser Center, 4105 Empire Drive, Bakersfield, CA, 93309, USA

Email dchang@empireeyeandlaser.com

\begin{abstract}
Presbyopia, a loss of accommodative ability associated with aging, is a significant cause of vision impairment globally. At the clinical level, it is a frustrating and difficult issue that negatively impacts patients' quality of life. Less appreciated is the fact that loss of accommodative ability and its current treatments methods may present safety concerns, for example, increasing the risk of falls. Therefore, a more complete understanding of treatment options with respect to how they relate to the natural ability of the eye is needed to improve decision making and to aid clinicians in individualizing treatment options. This article reviews the options for expanding functional through focus - a term coined to describe the ability of the eye to see at all distances with minimal latency - by how they vary the refractive power over time, across the visual field, between eyes, or across a range of distances.
\end{abstract}

Keywords: accommodation, presbyopia, functional through focus

\section{Introduction}

The loss of accommodation, a natural part of the lenticular aging process and the first stage of Dysfunctional Lens Syndrome, ${ }^{1}$ is a significant cause of vision impairment suggested to affect about one-quarter of the world's population. ${ }^{2}$ Globally, there are an estimated 1.8 billion people with presbyopia, including 128 million people in the US alone. ${ }^{2}$ The average age of onset is generally between 40 and 45 years $^{3}$ and varies depending on climate, heritage, ${ }^{4}$ and other individual factors. ${ }^{5-7}$ The burden of uncorrected presbyopia is significant, accounting for near vision impairment in an estimated 826 million people globally, ${ }^{2}$ resulting in an estimated $\$ 25$ billion loss in productivity among individuals younger than 65 years. $^{8}$ With increasing longevity, most people in the western world will spend almost half of their lives as presbyopes. ${ }^{9}$ It is a condition that results in loss of productivity and quality of life, ${ }^{10,11}$ and may create safety concerns, ${ }^{12}$ suggesting it should be treated as an important medical need rather than as a lifestyle decision.

Accommodation describes the mechanism by which the eye varies refractive power to focus on objects at different distances to provide the retina a clear, sharp image. ${ }^{13}$ Thomas Young is widely credited with confirming that the crystalline lens is the primary anatomical structure responsible for accommodation ${ }^{14}$ (reviewed in 15) ${ }^{15}$ and Helmholtz later described the role of ciliary muscle contraction and relaxation of the zonules in inducing lens thickening and curvature, which contribute to increased refractive power. ${ }^{16}$ Glasser and Kaufman subsequently verified that the movement of 
the accommodative structures was most consistent with the Helmholtz theory. ${ }^{17}$ More recently, the interrelationship of the zonular apparatus' components has been visually described in a computer-animated model by Goldberg. ${ }^{18}$ By extension, a loss of accommodative amplitude due to changes in these and other anatomic structures secondary to aging manifests as presbyopia. ${ }^{19}$ Taken together, this evidence highlights that presbyopia is a phenomenon resulting from losing the ability to accommodate, ${ }^{20}$ and, consequently, that the goal of treating presbyopia is to compensate for this inability. However, to our knowledge, there is no universally accepted word or term to describe the objective of accommodation: to see in clear focus at any distance with low or no latency. In this review, we will use the term "functional through focus with imperceptible latency" (or "functional through focus") to describe this concept. According to the definition presented here, presbyopia can thus be thought of as a loss of functional through focus.

There are often tradeoffs associated with manipulating the optical system, particularly when dealing with the complexity and dynamic nature of accommodation. For example, increasing depth of field using multifocal intraocular lenses may result in loss of visual quality and contrast sensitivity. ${ }^{21,22}$ Other approaches can be associated with more severe unintended effects. For example, multifocal spectacles increase the risk of falls in elderly individuals. ${ }^{23}$ A fuller understanding of the risks and benefits associated with various treatment approaches, beyond those that may be treatment related, requires a new way to think about them. As such, this article proposes a new system of classifying presbyopia interventions according to their mechanism of action.

\section{Background and Rationale}

Currently, presbyopia treatments are characterized according to the device used (ie, glasses and contact lenses) and/ or the procedure performed (ie, corneal refractive surgery and lenticular refractive surgery). This method-based classification is logical for historical and clinical purposes, facilitating at least a basic understanding of efficacy and safety outcomes related to the method of treatment. However, it provides little insight into the optical effects experienced by a given patient and thus little utility for prospective clinical decision making based on a patient's previous experience with presbyopia treatments. On the other hand, a more meaningful comparison would follow from classification by mechanism of action for achieving functional through focus. This would lend itself to a better understanding of the optical principles leveraged by a given intervention and the advantages and disadvantages associated with that mechanism.

Fundamentally, restoring functional through focus requires a varying of refractive power so that objects at different distances can be brought into focus with minimal latency. This can be achieved by leveraging at least one of four mechanisms that expand functional through focus by varying the refractive power (1) over time, (2) across the visual field, (3) between eyes, or (4) across a range of distances. These mechanisms can be used alone or in combination. The methods used to achieve the given mechanism of correction may be permanent or impermanent and can be applied at different extraocular or intraocular locations (eg, non-contact, on the surface, on the cornea, and intraocularly), which may or may not correspond to the location of the mechanistic effect (Table 1).

Considering the mechanism of action in the manner we propose provides a practical framework to understand the inherent advantages and disadvantages associated with treatment options, independent of the specific mode of intervention used to implement that mechanism (Table 2). For example, monovision leverages the mechanism of varying the refractive state between eyes. While there are subtle differences, the fundamental advantages and disadvantages of monovision are the same whether achieved via contact lenses, laser vision correction, or intraocular lenses (IOLs). As a result, a patient who is intolerant of monovision with contact lenses would likely not tolerate monovision with IOLs because both interventions share the same fundamental mechanism of action. Recognizing the underlying mechanism of action would allow a clinician to use a patient's previous presbyopia treatment experience as a factor in clinical decision making.

\section{Varying Refractive Power Over Time}

In the human visual system, focus is achieved when light from an object of regard is focused on the fovea (Figure 1). As the eye regards objects at different distances, functional through focus describes the ability of the eye to adjust the refractive power to bring the object into focus at the given distance. This mechanism is the only one that can facilitate uncompromised vision at any given distance. 


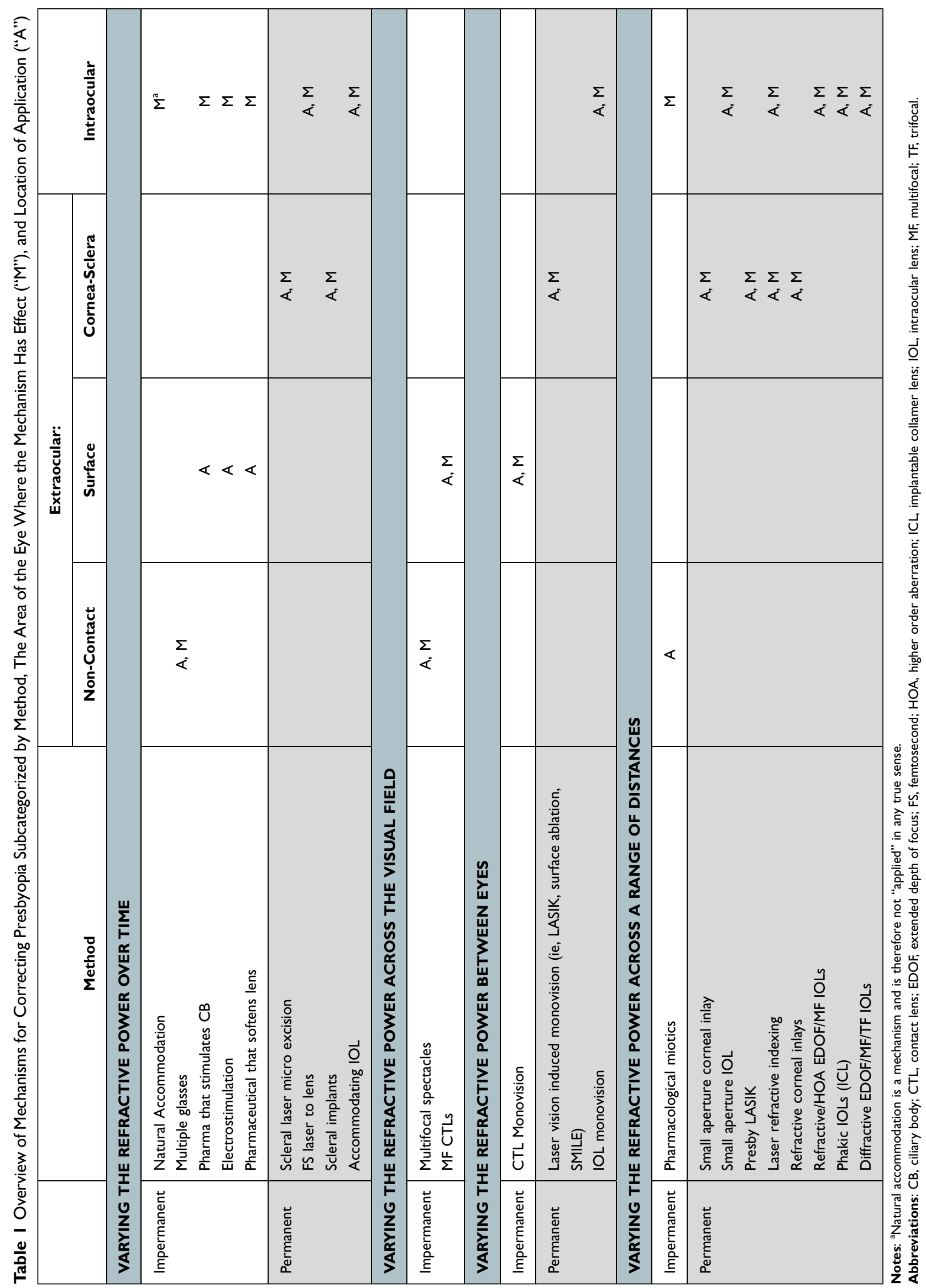


Table 2 Relative Advantages and Disadvantage of Differing Approaches for Varying Refractive Power to Achieve Functional Through Focus

\begin{tabular}{|c|c|c|}
\hline Mechanism & Advantages & Disadvantages \\
\hline Over time ${ }^{a}$ & $\begin{array}{l}\text { - Mimics natural mechanism } \\
\text { - Could achieve goal with no inherent side } \\
\text { effects }\end{array}$ & $\begin{array}{l}\text { - Technically challenging } \\
\text { - Has not been successfully achieved }\end{array}$ \\
\hline Across the visual field & $\begin{array}{l}\text { - Easy to implement } \\
\text { - Convenient } \\
\text { - Reversible }\end{array}$ & $\begin{array}{l}\text { - Potential visual intolerance/image jump } \\
\text { - } \text { Blurred inferior VF } \\
\text { - Requires neuroadaptation } \\
\text { - Potential for neck, eye strain } \\
\text { - Trip hazard }\end{array}$ \\
\hline Between eyes & $\begin{array}{l}\text { - } \text { Easy to implement } \\
\text { - } \text { Convenient } \\
\text { - } \\
\text { Reversible }\end{array}$ & $\begin{array}{l}\text { - Loss of visual quality, depth perception, contrast sensitivity, and stereo } \\
\text { acuity } \\
\text { - Potential visual intolerance } \\
\text { - Requires neuroadaptation } \\
\text { - Trip hazard, especially with incomplete suppression of interocular blur } \\
\text { - Inherent limits in binocular summation (may require residual } \\
\text { accommodation) }\end{array}$ \\
\hline $\begin{array}{l}\text { Across range of } \\
\text { distance }\end{array}$ & $\begin{array}{l}\text { - Most similar to natural accommodation } \\
\text { - Extends DOF }\end{array}$ & $\begin{array}{l}\text { - Potential loss of quality and contrast } \\
\text { - Potential low-light dysphotopsias } \\
\text { - Can require surgical precision }\end{array}$ \\
\hline
\end{tabular}

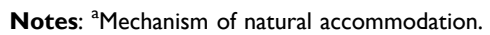

Abbreviations: DOF, depth of focus; VF, visual field.

Accommodation is the natural mechanism to achieve functional through focus with imperceptible latency. Helmholtz proposed that circumferential ciliary muscle contraction releases zonular tension, allowing the lens capsule to contract, increasing lens surface curvature, thus providing the dioptric power necessary for near visual tasks. ${ }^{16}$ This ability is reduced as the lens stiffens and becomes dysfunctional with age.

\section{Interventions}

Presbyopia is the loss of the eye's ability to vary the refractive power. ${ }^{19}$ Depending on the stage of presbyopia different approaches can be used to enhance or recreate this mechanism for creating functional through focus. Early in the progression of presbyopia, the residual accommodative amplitude can be enhanced; but in later stages, the only way to recreate the ability to vary refractive power over time is through artificial means.

Spectacles are the simplest method for changing the refractive state over time. While using different glasses for far and near visual tasks mechanistically varies the refractive power over time, it by necessity entails significant perceptible latency. Nonsurgical approaches include an eye drop that exerts ciliary muscle contraction as one of its mechanism for accentuating accommodation. Another
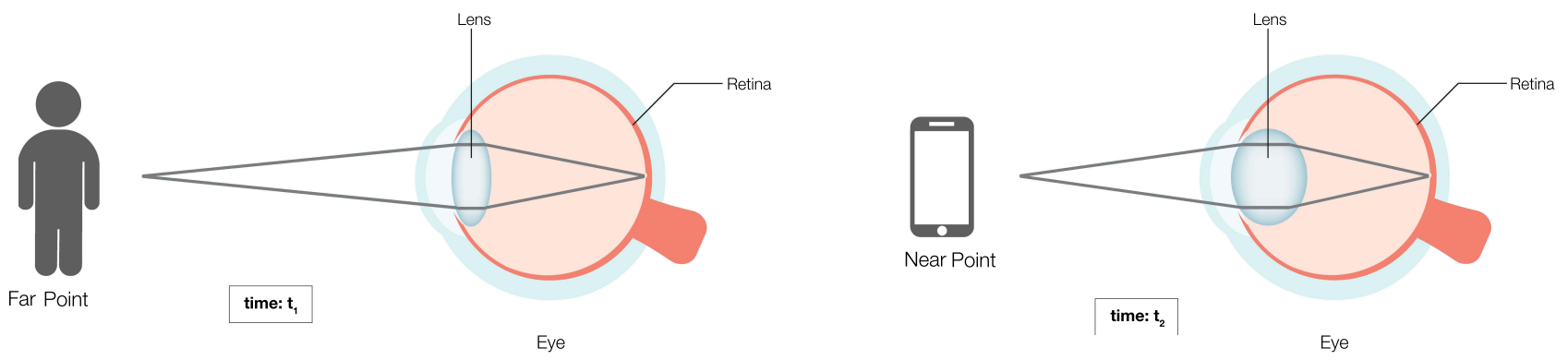

Figure I Varying the refractive power over time describes the eye's natural ability to shift focus from far objects (person) at time I ( $\left.t_{1}\right)$ to near (smartphone) at time 2 ( $\left.t_{2}\right)$. 
pharmaceutical option dissolves disulfide bonds, returning the lens to a more flexible state, thereby allowing for natural accommodative ability. ${ }^{24}$ Electrostimulation is a nonpharmaceutical approach for reviving ciliary muscle contraction. $^{25}$

Laser options include scleral laser micro-excision, in which an Er:YAG laser is applied to increase plasticity and compliance of the scleral tissue to facilitate contraction of the ciliary muscles, and femtosecond laser manipulation of the lens to increase its deformability, and thus accommodative ability. ${ }^{26,27}$ Other surgical options include implants which increase the area between the ciliary muscle and the sclera to restore accommodation. ${ }^{28}$

Accommodating IOLs (AIOLs) are intended to create a progressive change in power in relation to the active contraction of the ciliary body. ${ }^{29,30}$ Various design approaches including hinged, dual optic, bioanalogic polyfocal, and fluid optic designs have been studied. ${ }^{31-33}$

\section{Advantages and Disadvantages}

By varying the refractive power over time, objects at any distance can be seen in full focus by the full visual field of both eyes. Visual distortions, breaks in the visual field, and monocular disparity are theoretically avoided. For these reasons, restoration of natural accommodation or creation of artificial accommodation would conceptually be the ideal approach to treating presbyopia. Although no drug or device demonstrating true power change over time has received approval from the US Food and Drug Administration (FDA), one candidate pharmaceutical is currently undergoing review.
The technical challenges of creating a device that achieves functional through focus through accommodation are many, specifically automatically sensing the amount of accommodation needed; optically or mechanically varying the refractive power accordingly; and stability over time. All of this would need to be combined in a device with biocompatible materials implantable through a microincision at the time of lens extraction.

With no current FDA-approved presbyopia treatment in this category, it is not possible to assess safety and efficacy. The sole IOL to receive approval from the FDA with an accommodating label is the Crystalens IOL (Bausch \& Lomb, Bridgewater, NJ). However, this lens demonstrates limited objective accommodative response movement on aberrometry. ${ }^{34}$ Given that a convenient solution that varies the refractive state over time does not yet exist, patients have sought a variety of options that are more convenient, but which are associated with inherent compromises.

\section{Varying Refractive Power Across the Visual Field}

Broadly speaking, near visual tasks such as reading are typically performed in the lower visual field, while far tasks, such as driving and watching television, are performed using the central and upper visual field. Optical devices have been designed to leverage this tendency by providing different refractive powers corresponding to the direction of gaze (Figure 2). In order to be effective, the device must move independently with respect to the eye's direction of gaze.

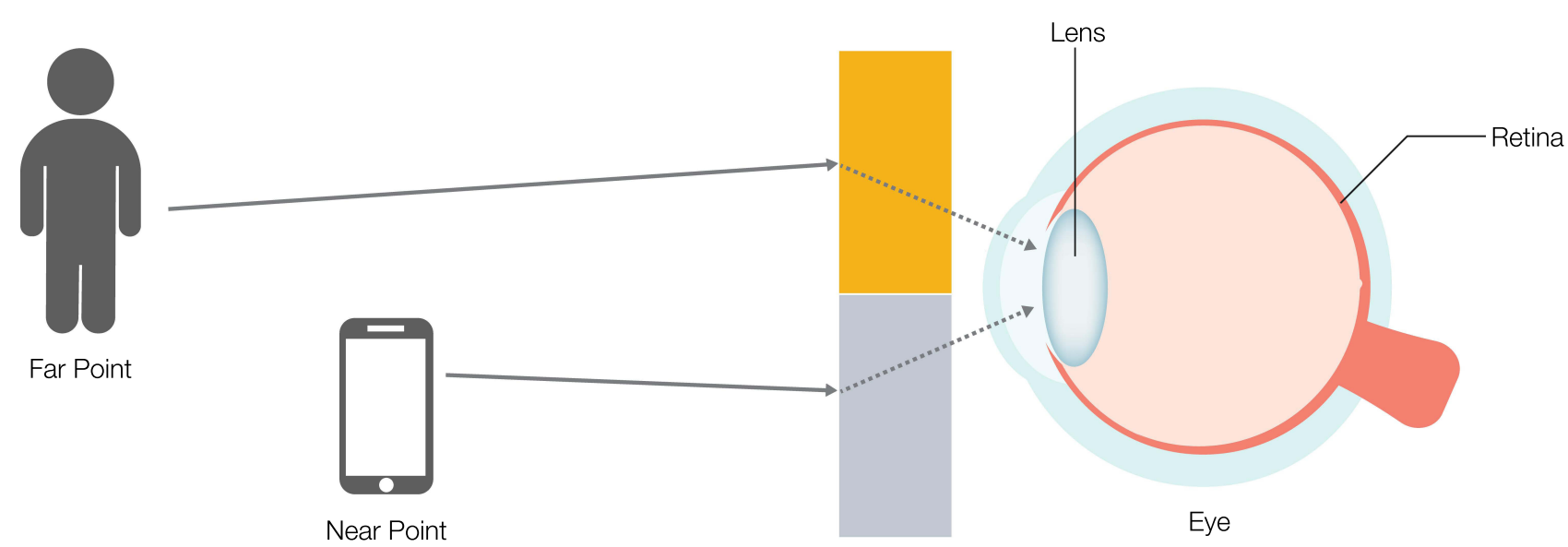

Figure 2 Varying the refractive power across the field requires optics that utilize two or more focusing zones. In this example, representing a bifocal correction, objects at far (person) are focused by an optic powered for far (orange rectangle), and objects at near (smartphone) are focused by an optic powered for near (grey rectangle). The viewer must either move the optic itself or physically adjust the eye gaze to utilize the appropriate viewing zone. 


\section{Interventions}

Multifocal spectacles are the prototypical example of a presbyopia treatment that varies the refractive power over the visual field. The invention of bifocal glasses is widely credited to Benjamin Franklin. ${ }^{35}$ Since that time, there have been various multifocal designs, including but not limited to flat top, round top, trifocal, and progressive add lenses. Certain multifocal contact lenses, specifically those with a segmented design, also leverage this mechanism. Although they may move with the eye, on down gaze, the lower lid prevents full downward movement of the lens, thus allowing the visual axis to pass through the higher-powered portion of the lens.

Notably, although multizone IOLs with nonrotationally symmetric power distribution may appear to vary refractive state across the visual field, they in fact leverage pseudoaccommodative principles due to the fact that they do not move independently from the eye gaze. ${ }^{36}$

\section{Advantages and Disadvantages}

Although a popular option, varying the refractive state across the visual field is associated with several drawbacks. Multifocal spectacles may require head and body movements when trying to focus on objects at different distances, and bifocal and trifocal spectacles may contribute to image jumps and distortions. Progressive add lenses offer a smoother transition in power, but outside of a narrow corridor along the lens surface, there is additional distortion. ${ }^{37}$ Multifocal spectacles of all types cause decreased edge-contrast sensitivity and depth perception in the inferior visual field, making it difficult to judge object position and movement. This has been shown to significantly increase risk of accidents and falls in the elderly. ${ }^{38}$ Direct medical costs due to falls attributable to multifocal spectacles are estimated to be approximately $\$ 11$ billion annually in the US. ${ }^{23}$

Similarly, multifocal contact lenses may result in visually problematic superimposition of images in settings of low contrast. ${ }^{39}$ Moreover, a number of factors may impact patients' ability to successfully wear contact lenses of any modality, ${ }^{40}$ which undermines their reliability as a suitable option for long-term management of presbyopia. As well, multiple viewing zones can reduce image quality and may result in halos, glares, or reduced nighttime vision. $^{41-43}$

\section{Varying the Refractive Power Between Eyes}

Natural binocularity provides redundancy in vision over all ranges with a slight parallax at near ranges, which the brain uses to facilitate depth perception. ${ }^{44}$ Leveraging the redundancy and breaking binocularity via establishment of differing refractive powers between the two eyes thus provides a fuller range of vision. ${ }^{45}$ Commonly referred to as monovision, varying the refractive state between eyes requires patients to employ binocular neural summation to add focused and defocused images in the visual cortex where non-linear summation or cross-eye neural inhibition is thought to reduce the visibility of the defocused image (Figure 3). ${ }^{46,47}$

\section{Interventions}

Monovision can be achieved using a variety of methods. In creating induced anisometropia, the refractive power of one eye (typically the dominant eye) is established for far vision while the contralateral eye is established for near. Contact lenses, while typically used to correct static refractive errors, naturally lend themselves to this mechanism. After determining the power required to establish emmetropia, a separate strategy is needed to determine the degree of controlled anisometropia required to treat the presbyopia. Of note, leveraging this mechanism is often coupled with some degree of varying the refractive power across a range of distances (ie, pseudoaccommodation) with concentric or aspheric multifocal contact lenses to achieve even greater through focus.

This mechanism can also be utilized through various surgical approaches. Functionally, corneal and lenticular refractive surgery have the same visual effect as contact lenses. In addition to correcting static refractive errors, LASIK, PRK, and IOLs can be used to vary the refractive power between eyes, thus improving through focus. As is the case with multifocal contact lenses, presby LASIK and certain IOLs leverage some degree of pseudoaccommodation to increase depth of focus. ${ }^{28,48}$

\section{Advantages and Disadvantages}

Monovision is relatively easy to implement and works for many individuals ${ }^{49-52}$ but may not be tolerated by some. ${ }^{45}$ Success with monovision is dependent on suppression of interocular blur. ${ }^{53}$ Incomplete suppression may be a safety concern, as monocular blur increases the risk of falls. ${ }^{54,55}$ Furthermore, for most patients, binocular summation is 


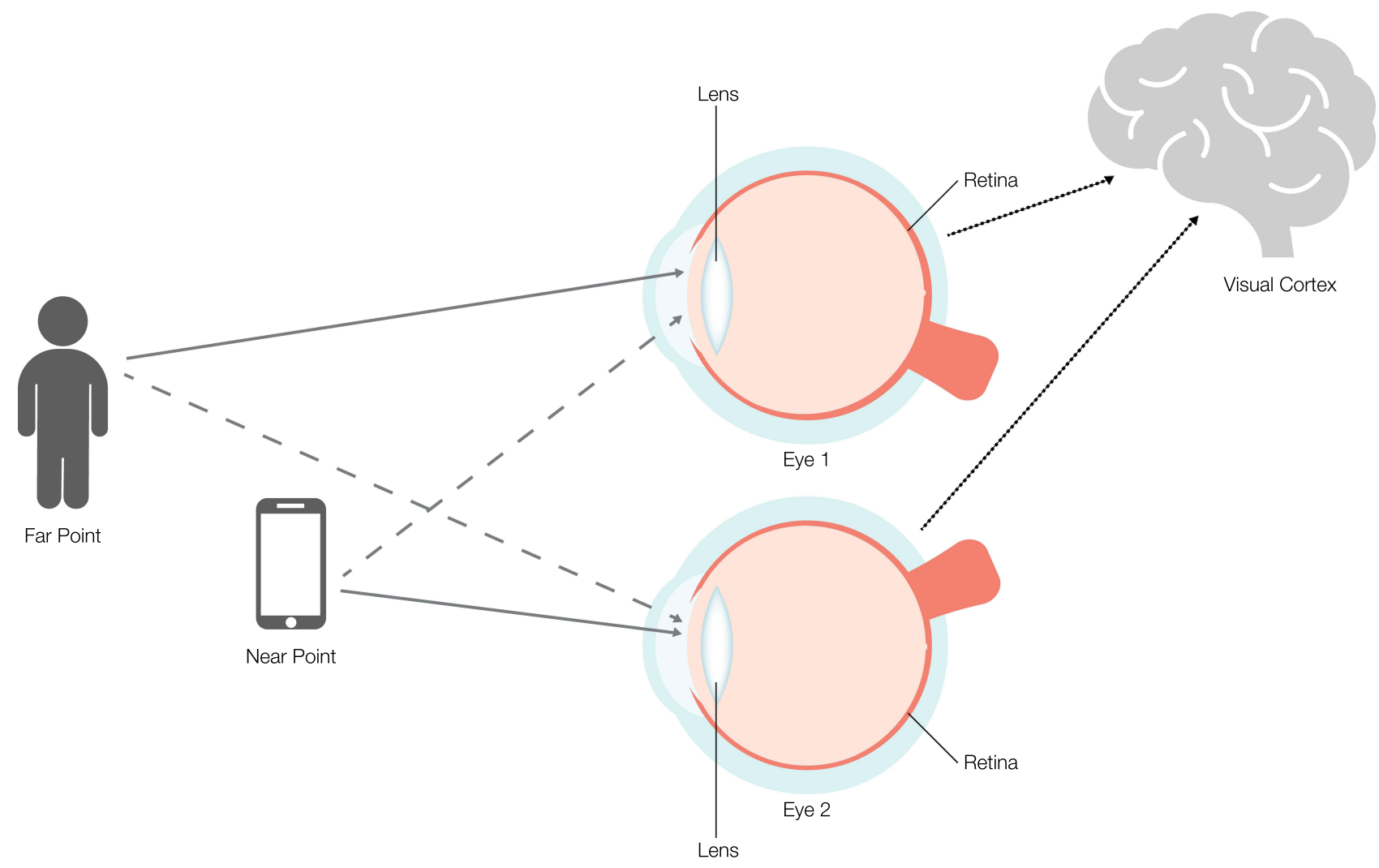

Figure 3 Varying the refractive power between eyes, or monovision, ultimately depends on binocular summation within the visual cortex of the brain. Objects at far (person) are focused by one eye (Eye I) that is appropriately powered for viewing (indicated by a solid arrow) and a defocused image (indicated by a dashed arrow) is perceived by the fellow eye (Eye 2). The opposite is true for near objects (smartphone). The resulting image is reorganized via binocular neural summation to add focused and defocused images in the visual cortex.

limited to a contralateral difference of $1.5 \mathrm{D} .{ }^{56}$ Higher adds may result in binocular inhibition. Therefore, successful implementation of monovision appears to benefit from residual accommodation, and thus may be insufficient in advanced and pseudophakic presbyopia.

Monovision is frequently associated with a reduction of peak acuity, loss of contrast sensitivity, and compromise in stereo acuity. ${ }^{45,57}$ It also negatively affects quality of vision at all ranges and depth perception. ${ }^{58}$ As a consequence, it may not be suitable for patients in whom binocular vision and depth perception are particularly critical to their career or lifestyle. There is evidence that monovision may affect the ability to properly perceive motion, especially at far distance. ${ }^{59}$ Additionally, monovision has been found to impair the ability of elderly patients to effectively judge raised surfaces, thereby contributing to falls. ${ }^{54}$ Indeed, epidemiological studies have shown an association between decreased monocular visual acuity and stereoacuity and an increased risk of falls and hip fractures in the elderly. ${ }^{23,60}$

\section{Varying the Refractive Power Across a Range of Distance}

Varying the refractive state across a range of distances refers to the creation of simultaneous focus through far, intermediate, and near (Figure 4). With this mechanism, objects at all distances appear in simultaneous focus, and thus continuity across the field of view and between eyes is preserved. ${ }^{61}$ This is commonly referred to as pseudoaccommodation. Pseudoaccommodation can have different patterns as characterized by its defocus curve, and it can be achieved by different techniques and at different locations. ${ }^{61}$ Pseudoaccommodation is distinct from pseudophakic accommodation, with the latter referring to the dynamic change in refractive state due to movement of the IOL/bag complex. ${ }^{62}$ As noted above, it can be combined with other mechanisms, such as monovision.

The defocus curve pattern of pseudoaccommodation can be broadly defined by the presence or absence of discrete ranges of sharper focus. Multifocal (bifocal and/ or trifocal) technologies create two or more specific ranges 


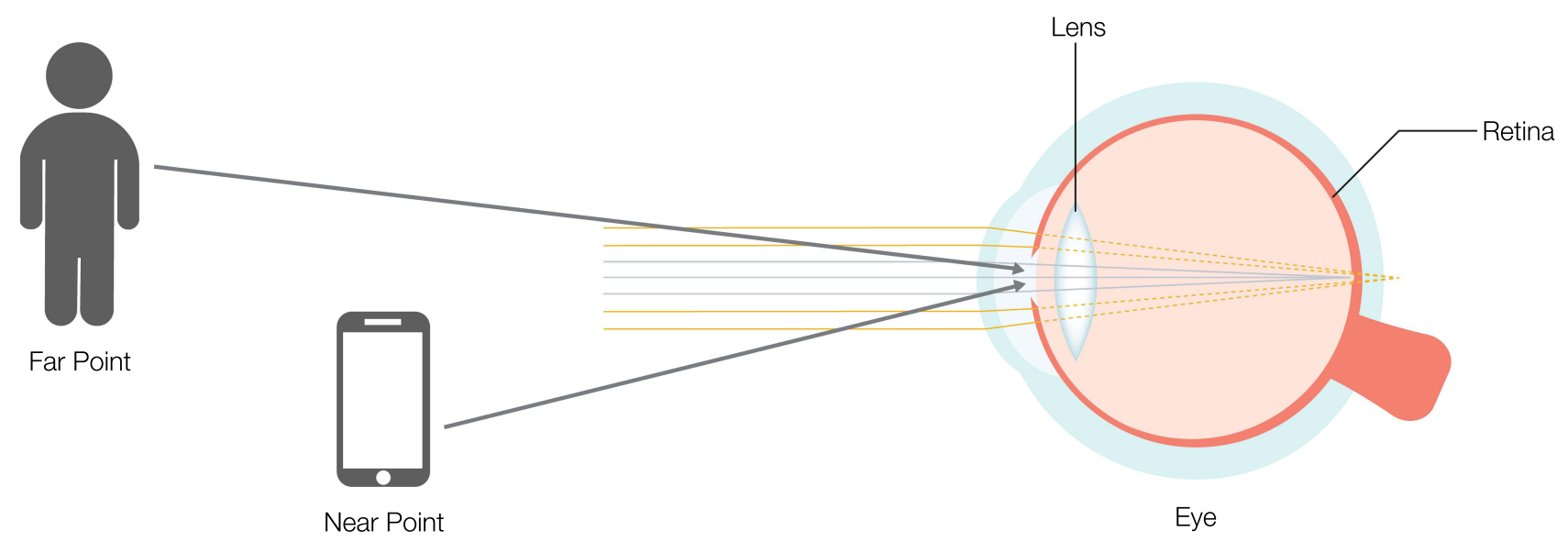

Figure 4 Varying the refractive power across a range of distances (pseudoaccomodation) achieves simultaneous focus from far (person) to near (smartphone). In this illustration, an iris pinhole optic provides pseudoaccomodative ability.

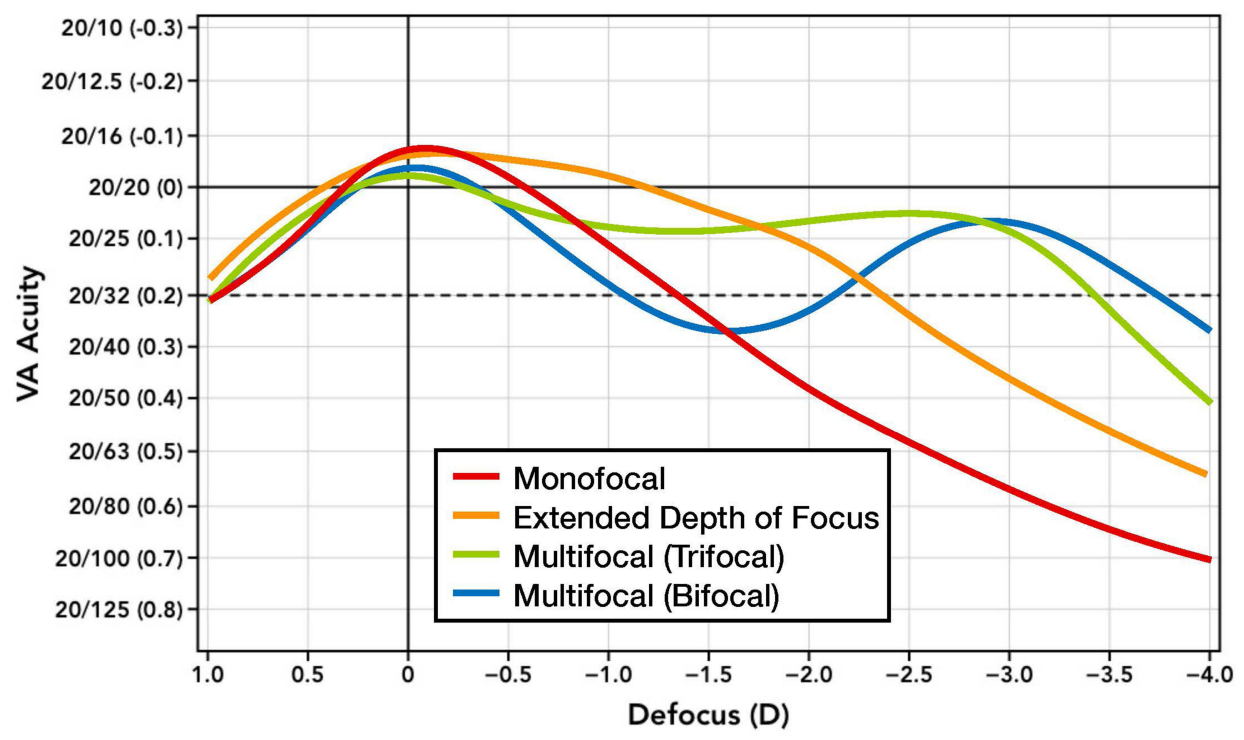

Figure 5 Representative defocus curves associated with various methods for varying the refractive power across a range of distances.

of best focus while extended depth of focus technologies are characterized by a single broader range with no inflections in the defocus curve (Figure 5). Clinically, multifocal defocus curves manifest as objects coming in, out, and back in focus when brought from far to near, while extended depth of focus curves manifests as objects remaining in focus when moving throughout the pseudoaccommodative range.

\section{Interventions}

Multiple methods can be used to achieve pseudoaccommodation. They can be categorized by the optical principle leveraged to increase the depth of field: small aperture, refractive, and diffractive optics (Figure 6).
The small aperture, or pinhole effect, extends the depth of focus by blocking unfocused, peripheral light rays and permitting only central light rays to reach the retina. ${ }^{48,63}$ Various corneal inlays ${ }^{64}$ and IOLs ${ }^{65}$ have been designed utilizing small aperture optics, and several studies are evaluating pharmaceutical eyedrops, such as pilocarpine HCL 1.25\% (AGN-190584; Allergan, an AbbVie company; Chicago), that induce a similar effect. ${ }^{66-68}$ The latter uses the iris to create the pinhole effect, which has the advantage of modulating the existing aperture as opposed to adding a second aperture.

Refractive optics utilize various zones to focus incoming light rays from different distances to create a broader 

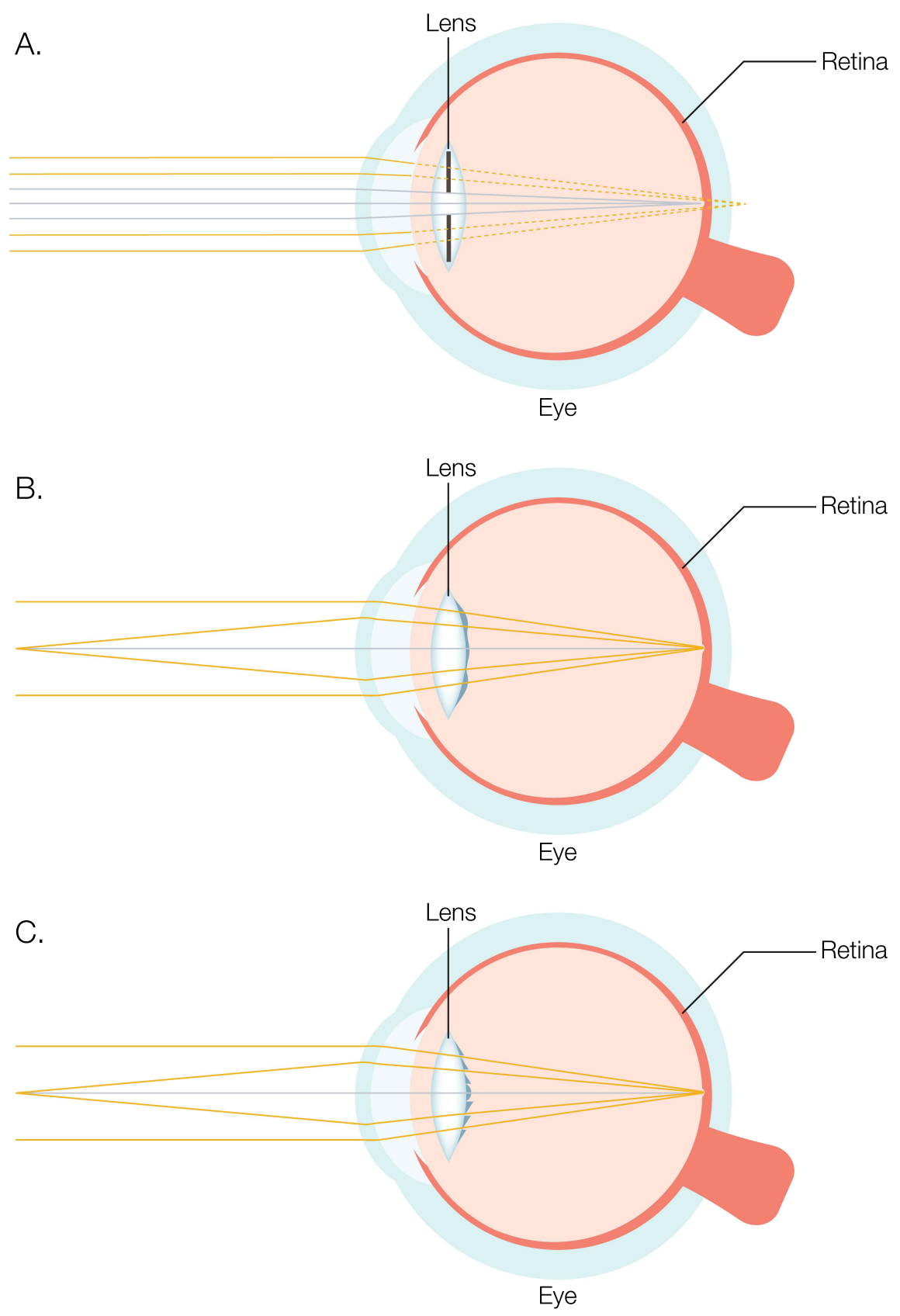

Figure 6 Varying refractive power across a range of distances may be accomplished by one of three mechanisms. Small Aperture/Pinhole Optics (A) function to block peripheral unfocused light rays, while focused light rays reach the retina. Refractive Optics (B) utilize multiple focusing zones. Diffractive Optics (C) leverage interference patterns to create zones/ranges of focus from far to near.

range of focus on the retina. Patterns of refractive contact lens optics include concentric and aspheric designs. ${ }^{69}$ In presby LASIK, a customized ablation pattern creates a multifocal cornea, ${ }^{70}$ whereas with refractive corneal inlays, the addition of the implant achieves a similar effect. With refractive multifocal IOLs, the zones of different power can be in concentric, aspheric, segmental, and combined patterns. ${ }^{69}$
Diffractive optics create a phase shift of the incoming wavefront to create an expanded range of focus so that objects at different distances appear in focus. At current, available diffractive optics employ microscopic steps on the lens surface to create the phase shift necessary to achieve the desired diffractive pattern. ${ }^{71}$ Varying the height, spacing, and profile of the steps, multifocal, trifocal, and extended depth of focus patterns of increasing through focus have been created. 
Finally, laser refractive indexing can theoretically modify the optics of the cornea or an existing implant both through refractive and diffractive means to create multifocality by selectively modifying the refractive index of a tissue or material. ${ }^{72}$

\section{Advantages and Disadvantages}

The specific effects of pseudoaccommodation depend on the method used to expand the visual range. When appropriately applied, small aperture optics can improve visual acuity at near and intermediate distances without negatively impacting far vision, reducing binocular contrast sensitivity, or increasing dysphotopsias. ${ }^{64}$ However, when the aperture is too small, or when a second aperture is introduced, and possibly misaligned, visual quality can be degraded and peripheral vision can be compromised. ${ }^{63}$

Application of pseudoaccommodation via refractive and diffractive multifocal optics is successful in many patients, providing functional vision at far, intermediate, and near. ${ }^{73}$ The two primary disadvantages of pseudoaccommodative optics are potential compromise in visual quality and incidence of bothersome low light dysphotopsias. These potential side effects are inherent to this method of expanding through focus. Therefore, attention to reduction of monochromatic and chromatic aberrations, as well as lens profile and chromophore considerations, is essential to have a successful product.

\section{Conclusion}

Understanding presbyopia treatments according to their mechanism of action confers several benefits. From a broad perspective, such a classification system permits a fuller understanding of how closely the given intervention or treatment replicates the physiologic processes that provide the human eye the ability to see in clear focus at any distance with low or no latency. For the clinician, an understanding of mechanisms facilitates clinical decisionmaking. When offering a treatment option to the patient, the clinician can use prior experiences as a guide. For example, patients who exhibit a suboptimal presbyopia correction with multifocal contact lenses may have difficulties with multifocal IOLs, as the latter utilizes the same mechanism. Instead, the clinician can consider an alternative option that leverages one or more of the other mechanisms noted above.

In some cases, functional through focus can be achieved with a combination of mechanisms. One example may be using an extended depth of focus lens in each eye set at different powers to achieve a mini-monovision arrangement. In this hypothetical example, the overall correction leverages two mechanisms: varying refractive power over a range of distances and between eyes. Similarly, corneal inlays and presby-LASIK can vary the refractive power across a range of distances, and when performed in only one eye, also vary the refractive power between eyes. Thus, the categories described herein can be used in combination in certain clinical settings as building blocks for achieving functional through focus in the correction of presbyopia.

Historically, the treatment of presbyopia has been combined with refractive correction. However, doing so requires greater precision than addressing either problem on its own. Decoupling presbyopia treatment from refractive correction can lower the barrier to restoring functional through focus. This consideration will become even more relevant as newer treatment options become available.

An important limitation to this classification system should be acknowledged. Specifically, at present, there are only limited ways to measure the specific pathologic features contributing to loss of accommodative ability in a given patient. Moreover, the understanding of the exact mechanisms of accommodation is unsettled. Although widely considered the most accurate description of the physiology associated with accommodation, the Helmholtz theory ${ }^{16}$ is disputed by other authors. ${ }^{74}$ Taken together, these facts underscore that any classification system is inherently limited by the extent of the current knowledge base. However, they also suggest an opportunity: as eye models evolve, and as new means of measuring the various mechanisms associated with loss of accommodation become available, the existing framework presented in this article can be updated accordingly.

Fundamentally, we propose this new classification schema because presbyopia treatment should be thought of in terms of medical need rather than as a lifestyle decision. The increasing prevalence of presbyopia ${ }^{2}$ stands to account for significant financial burden ${ }^{8}$ while negatively impacting patients' quality of life and daily living.${ }^{10,11}$ As well, loss of functional through focus is a safety concern. ${ }^{12}$ However, what may be under appreciated is that some treatments also introduce safety concerns, ${ }^{38}$ with substantial implications for direct medical costs. ${ }^{23}$ Thus, a more meaningful comparison of treatment options based on an understanding of the optical principles leveraged by a given intervention would bring the clinician closer to understanding the true goal of correcting 
presbyopia: restoring or mimicking the human eye's natural ability to achieve functional through-focus with imperceptible latency.

\section{Compliance with Ethics Guidelines}

This article is based on previously conducted studies and does not contain any new studies with human participants or animals performed by any of the authors.

\section{Medical Writing, Editorial, and Other Assistance}

Editorial assistance in the preparation of this article was provided by Bryan Bechtel of Bechtel Editorial Services, LLC. Support for this assistance was funded by Allergan, an AbbVie Company.

\section{Consent for Publication}

All tables and figures used in this publication are the work of the authors and are original.

\section{Author Contributions}

All named authors meet the International Committee of Medical Journal Editors (ICMJE) criteria for authorship for this article, take responsibility for the integrity of the work as a whole, and have given their approval for this version to be published. All authors made a significant contribution to the work reported, whether that is in the conception, study design, execution, acquisition of data, analysis and interpretation, or in all these areas; took part in drafting, revising or critically reviewing the article; gave final approval of the version to be published; have agreed on the journal to which the article has been submitted; and agree to be accountable for all aspects of the work.

\section{Funding}

This review was supported by Allergan plc, Dublin, Ireland (prior to its acquisition by AbbVie Inc.). Neither honoraria nor payments were made for authorship.

\section{Disclosure}

Dr. Chang declares that he is a consultant to and has received research support from Allergan/Abbie and Johnson \& Johnson Vision, and that he has received research support from AcuFocus, Inc, and personal fees from Carl Zeiss Meditec, outside the submitted work. Dr. Barnett declares that she is a consultant to Allergan/ AbbVie and Visus Therapeutics. Dr. Hom declares that he has received research support from the following: AbbVie/Allergan, Novartis, Kala, Tarsus, Hovione Scientia, Silk-tech, Sydnexis, Eyenovia, Surface, Nevakar, AstaReal, and Vyluma; and that he is a consultant to AbbVie/Allergan, Bausch, Novartis, Sun, Kala, Tarsus, laboratoires Thea, Eyevance, Visus, Aperta, and Azura. Dr. Waring declares that he is a consultant to Johnson \& Johnson Vision, Allergan/AbbVie, Perfect Lens, and ACE Vision Group. The authors report no other conflicts of interest in this work.

\section{References}

1. Waring GO, Rocha KM. Characterization of the dysfunctional lens syndrome and a review of the literature. Curr Ophthalmol Rep. 2018;6(4):249-255. doi:10.1007/s40135-018-0190-3

2. Fricke TR, Tahhan N, Resnikoff S, et al. Global prevalence of presbyopia and vision impairment from uncorrected presbyopia: systematic review, meta-analysis, and modelling. Ophthalmology. 2018;125(10):1492-1499. doi:10.1016/j.ophtha.2018.04.013

3. Pointer JS. The presbyopic add. II. Age-related trend and a gender difference. Ophthalmic Physiol Opt. 1995;15(4):241-248. doi:10.1046/j.1475-1313.1995.9400022r.x

4. Holden BA, Fricke TR, Ho SM, et al. Global vision impairment due to uncorrected presbyopia. Arch Ophthalmol. 2008;126(12):17311739. doi:10.1001/archopht.126.12.1731

5. Burke AG, Patel I, Munoz B, et al. Population-based study of presbyopia in rural Tanzania. Ophthalmology. 2006;113(5):723-727. doi:10.1016/j.ophtha.2006.01.030

6. Pointer JS. The presbyopic add. III. Influence of the distance refractive type. Ophthalmic Physiol Opt. 1995;15(4):249-253. doi:10.1046/ j.1475-1313.1995.9400023s.x

7. Pointer JS. Gender-related optical aspects of the onset of presbyopia. Ophthalmic Physiol Opt. 2002;22(2):126-129. doi:10.1046/j.14751313.2002.00012.x

8. Frick KD, Joy SM, Wilson DA, Naidoo KS, Holden BA. The global burden of potential productivity loss from uncorrected presbyopia. Ophthalmology. 2015;122(8):1706-1710. doi:10.1016/j. ophtha.2015.04.014

9. Charman WN. Developments in the correction of presbyopia I spectacle and contact lenses. Ophthalmic Physiol Opt. 2014;34 (1):8-29. doi:10.1111/opo.12091

10. Goertz AD, Stewart WC, Burns WR, Stewart JA, Nelson LA. Review of the impact of presbyopia on quality of life in the developing and developed world. Acta Ophthalmol. 2014;92(6):497-500. doi:10.1111/aos. 12308

11. Patel I, Munoz B, Burke AG, et al. Impact of presbyopia on quality of life in a rural African setting. Ophthalmology. 2006;113(5):728734. doi:10.1016/j.ophtha.2006.01.028

12. Wolffsohn JS, Leteneux-Pantais C, Chiva-Razavi S, et al. Social media listening to understand the lived experience of presbyopia: systematic search and content analysis study. $J$ Med Internet Res. 2020;22(9):e18306. doi:10.2196/18306

13. American Optometric Association. Care of the Patient with Presbyopia. St. Louis (MO): American Optometric Association; 2010.

14. Atchison DA, Charman WN. Thomas Young's contribution to visual optics: the Bakerian Lecture "on the mechanism of the eye. $J$ Vis. 2010;10(12):16. doi:10.1167/10.12.16

15. Ovenseri-Ogbomo GO, Oduntan OA. Mechanism of accommodation: a review of theoretical propositions. Afr Vision Eye Health. 2015;74 (1):6. doi:10.4102/aveh.v74i1.28 
16. Southall JPC, ed. Helmholtz's Treatise on Physiological Optics. Translated from the 3rd German Ed. New York: Dover Publications; 1962.

17. Glasser A, Kaufman PL. The mechanism of accommodation in primates. Ophthalmology. 1999;106(5):863-872. doi:10.1016/s01616420(99)00502-3

18. Goldberg DB. Computer-animated model of accommodation and presbyopia. $J$ Cataract Refract Surg. 2015;41(2):437-445. doi:10.1016/j.jcrs.2014.07.028

19. Harvard Health Publishing. Medical dictionary of health terms; 2021. Available from: https://www.health.harvard.edu/medical-dictionaryof-health-terms/j-through-p\#P-terms. Accessed March 10, 2021.

20. Croft MA, Glasser A, Kaufman PL. Accommodation and presbyopia. Int Ophthalmol Clin. 2001;41(2):33-46. doi:10.1097/00004397200104000-00005

21. Lichtinger A, Rootman DS. Intraocular lenses for presbyopia correction: past, present, and future. Curr Opin Ophthalmol. 2012;23 (1):40-46. doi:10.1097/ICU.0b013e32834cd5be

22. Torricelli AA, Junior JB, Santhiago MR, Bechara SJ. Surgical management of presbyopia. Clin Ophthalmol. 2012;6:1459-1466. doi:10.2147/opth.s35533

23. Chang DH. Multifocal spectacle and monovision treatment of presbyopia and falls in the elderly. $J$ Refract Surg. 2021;37(S1):S12-S16. doi:10.3928/1081597X-20210408-02

24. Korenfeld MS, Robertson SM, Stein JM, et al. Topical lipoic acid choline ester eye drop for improvement of near visual acuity in subjects with presbyopia: a safety and preliminary efficacy trial. Eye (Lond). 2021. doi:10.1038/s41433-020-01391-z

25. Gualdi L, Gualdi F, Rusciano D, et al. Ciliary muscle electrostimulation to restore accommodation in patients with early presbyopia: preliminary results. $J$ Refract Surg. 2017;33(9):578-583. doi:10.3928/1081597x-20170621-05

26. Lubatschowski H, Schumacher S, Fromm M, et al. Femtosecond lentotomy: generating gliding planes inside the crystalline lens to regain accommodation ability. J Biophoton. 2010;3(5-6):265-268. doi:10.1002/jbio. 201000013

27. Schumacher S, Oberheide U. Femtosecond lentotomy: a prospect for a treatment to regain the accommodation ability. In: Nolte $\mathrm{S}$, Schrempel F, Dausinger F, editors. Ultrashort Pulse Laser Technology. Springer Series in Optical Sciences. Vol. 195. Cham: Springer; 2016: 285-309. doi:10.1007/978-3-319-17659-8_13

28. Hipsley A, Hall B, Rocha KM. Scleral surgery for the treatment of presbyopia: where are we today? Eye Vis (Lond). 2018;5:4. doi:10.1186/s40662-018-0098-x

29. Alió JL, Alió Del Barrio JL, Vega-Estrada A. Accommodative intraocular lenses: where are we and where we are going. Eye Vis (Lond). 2017;4:16. doi:10.1186/s40662-017-0077-7

30. Liang YL, Jia SB. Clinical application of accommodating intraocular lens. Int J Ophthalmol. 2018;11(6):1028-1037. doi:10.18240/ijo.2018.06.22

31. Ossma IL, Galvis A, Vargas LG, Trager MJ, Vagefi MR, McLeod SD. Synchrony dual-optic accommodating intraocular lens. Part 2: pilot clinical evaluation. J Cataract Refract Surg. 2007;33(1):47-52. doi:10.1016/j.jcrs.2006.08.049

32. Alió JL, Ben-nun J, Rodríguez-Prats JL, Plaza AB. Visual and accommodative outcomes 1 year after implantation of an accommodating intraocular lens based on a new concept. $J$ Cataract Refract Surg. 2009;35(10):1671-1678. doi:10.1016/j.jcrs.2009.04.043

33. Studeny P, Krizova D, Urminsky J. Clinical experience with the WIOL-CF accommodative bioanalogic intraocular lens: Czech National Observational Registry. Eur J Ophthalmol. 2016;26 (3):230-235. doi:10.5301/ejo.5000653

34. Pérez-Merino P, Birkenfeld J, Dorronsoro C, et al. Aberrometry in patients implanted with accommodative intraocular lenses. $\mathrm{Am} \mathrm{J}$ Ophthalmol. 2014;157(5):1077-1089. doi:10.1016/j.ajo.2014.02.013

35. Letocha CE. The invention and early manufacture of bifocals. Surv Ophthalmol. 1990;35(3):226-235. doi:10.1016/0039-6257(90)90092-a
36. Alió JL, Piñero DP, Plaza-Puche AB, Chan MJ. Visual outcomes and optical performance of a monofocal intraocular lens and a newgeneration multifocal intraocular lens. J Cataract Refract Surg. 2011;37(2):241-250. doi:10.1016/j.jcrs.2010.08.043

37. Sheedy JE, Campbell C, King-Smith E, Hayes JR. Progressive powered lenses: the Minkwitz theorem. Optom Vis Sci. 2005;82(10):916922. doi:10.1097/01.opx.0000181266.60785.c9

38. Lord SR, Dayhew J, Howland A, Howland A. Multifocal glasses impair edge-contrast sensitivity and depth perception and increase the risk of falls in older people. $J$ Am Geriatr Soc. 2002;50(11):17601766. doi:10.1046/j.1532-5415.2002.50502.x

39. Charman WN, Saunders B. Theoretical and practical factors influencing the optical performance of contact lenses for the presbyope. $\mathrm{J} \mathrm{Br}$ Contact Lens Ass. 1990;13:67-75. doi:10.1016/0141-7037(90)80012-Q

40. Woods RL. The aging eye and contact lenses - a review of ocular characteristics. $J \mathrm{Br}$ Contact Lens Ass. 1991;14:115-127. doi:10.1016/0141-7037(91)80004-6

41. Chu BS, Wood JM, Collins MJ. The effect of presbyopic vision corrections on nighttime driving performance. Invest Ophthalmol Vis Sci. 2010;51(9):4861-4866. doi:10.1167/iovs.10-5154

42. Cochener B, Lafuma A, Khoshnood B, Courouve L, Berdeaux G. Comparison of outcomes with multifocal intraocular lenses: a metaanalysis. Clin Ophthalmol. 2011;5:45-56. doi:10.2147/opth.s14325

43. Maxwell WA, Lane SS, Zhou F. Performance of presbyopia-correcting intraocular lenses in distance optical bench tests. $J$ Cataract Refract Surg. 2009;35(1):166-171. doi:10.1016/j.jcrs.2008.10.026

44. Qian N. Binocular disparity and the perception of depth. Neuron. 1997;18(3):359-368. doi:10.1016/s0896-6273(00)81238-6

45. Evans BJ. Monovision: a review. Ophthalmic Physiol Opt. 2007;27 (5):417-439. doi:10.1111/j.1475-1313.2007.00488.x

46. Blake R, Logothetis N. Visual competition. Nat Rev Neurosci. 2002;3 (1):13-21. doi:10.1038/nrn701

47. Polonsky A, Blake R, Braun J, Heeger DJ. Neuronal activity in human primary visual cortex correlates with perception during binocular rivalry. Nat Neurosci. 2000;3(11):1153-1159. doi:10.1038/ 80676

48. Charman WN. Developments in the correction of presbyopia II: surgical approaches. Ophthalmic Physiol Opt. 2014;34(4):397-426. doi:10.1111/opo.12129

49. Finkelman YM, Ng JQ, Barrett GD. Patient satisfaction and visual function after pseudophakic monovision. J Cataract Refract Surg. 2009;35(6):998-1002. doi:10.1016/j.jcrs.2009.01.035

50. Greenbaum S. Monovision pseudophakia. J Cataract Refract Surg. 2002;28(8):1439-1443. doi:10.1016/s0886-3350(02)01218-x

51. Ito M, Shimizu K. Reading ability with pseudophakic monovision and with refractive multifocal intraocular lenses: comparative study. $J$ Cataract Refract Surg. 2009;35(9):1501-1504. doi:10.1016/j. jcrs.2009.03.051

52. Marques FF, Sato RM, Chiacchio BB, Marques DM, Barreiro J, Caetano RL. Evaluation of visual performance and patient satisfaction with pseudophakic monovision technique. Arq Bras Oftalmol. 2009;72(2):164-168. doi:10.1590/s0004-27492009000200006

53. Schor C, Landsman L, Erickson P. Ocular dominance and the interocular suppression of blur in monovision. Am J Optom Physiol Opt. 1987;64(10):723-730. doi:10.1097/00006324-198710000-00002

54. Vale A, Buckley JG, Elliott DB. Gait alterations negotiating a raised surface induced by monocular blur. Optom Vis Sci. 2008;85 (12):1128-1134. doi:10.1097/OPX.0b013e31818e8d2a

55. Vale A, Scally A, Buckley JG, Elliott DB. The effects of monocular refractive blur on gait parameters when negotiating a raised surface. Ophthalmic Physiol Opt. 2008;28(2):135-142. doi:10.1111/j.14751313.2008.00543.x

56. Hayashi K, Yoshida M, Manabe S, Hayashi H. Optimal amount of anisometropia for pseudophakic monovision. J Refract Surg. 2011;27 (5):332-338. doi:10.3928/1081597x-20100817-01 
57. Durrie DS. The effect of different monovision contact lens powers on the visual function of emmetropic presbyopic patients (an American Ophthalmological Society thesis). Trans Am Ophthalmol Soc. 2006;104:366-401.

58. Kollbaum PS, Bradley A. Correction of presbyopia: old problems with old (and new) solutions. Clin Exp Optom. 2020;103(1):21-30. doi:10.1111/cxo.12987

59. Burge J, Rodriguez-Lopez V, Dorronsoro C. Monovision and the misperception of motion. Curr Biol. 2019;29(15):2586-2592.e4. doi:10.1016/j.cub.2019.06.070

60. Felson DT, Anderson JJ, Hannan MT, Milton RC, Wilson PW, Kiel DP. Impaired vision and hip fracture. The Framingham Study. $J \mathrm{Am}$ Geriatr Soc. 1989;37(6):495-500. doi:10.1111/j.1532-5415.1989. tb05678.x

61. Nishi T, Taketani F, Ueda T, Ogata N. Comparisons of amplitude of pseudoaccommodation with aspheric yellow, spheric yellow, and spheric clear monofocal intraocular lenses. Clin Ophthalmol. 2013;7:2159-2164. doi:10.2147/opth.s52771

62. Patel R, Wang L, Koch DD, Yeu E. Pseudoaccommodation. Int Ophthalmol Clin. 2011;51(2):109-118. doi:10.1097/ IIO.0b013e31820f2748

63. Charman WN. Pinholes and presbyopia: solution or sideshow? Ophthalmic Physiol Opt. 2019;39(1):1-10. doi:10.1111/opo.12594

64. Seyeddain O, Hohensinn M, Riha W, et al. Small-aperture corneal inlay for the correction of presbyopia: 3-year follow-up. J Cataract Refract Surg. 2012;38(1):35-45. doi:10.1016/j.jcrs.2011.07.027

65. Dick HB, Piovella M, Vukich J, Vilupuru S, Lin L. Prospective multicenter trial of a small-aperture intraocular lens in cataract surgery. J Cataract Refract Surg. 2017;43(7):956-968. doi:10.1016/j. jcrs.2017.04.038

66. Vargas V, Vejarano F, Alió JL. Near vision improvement with the use of a new topical compound for presbyopia correction: a prospective, consecutive interventional non-comparative clinical study. Ophthalmol Ther. 2019;8(1):31-39. doi:10.1007/s40123-018-0154-6
67. Benozzi J, Benozzi G, Orman B. Presbyopia: a new potential pharmacological treatment. Med Hypothesis Discov Innov Ophthalmol. 2012;1(1):3-5.

68. Abdelkader A. Improved presbyopic vision with miotics. Eye Contact Lens. 2015;41(5):323-327. doi:10.1097/icl.0000000000000137

69. Terwee T, Weeber H, van der Mooren M, Piers P. Visualization of the retinal image in an eye model with spherical and aspheric, diffractive, and refractive multifocal intraocular lenses. J Refract Surg. 2008;24 (3):223-232. doi:10.3928/1081597x-20080301-03

70. Vargas-Fragoso V, Alió JL. Corneal compensation of presbyopia: presbyLASIK: an updated review. Eye Vis (Lond). 2017;4:11. doi:10.1186/s40662-017-0075-9

71. Davison JA, Simpson MJ. History and development of the apodized diffractive intraocular lens. J Cataract Refract Surg. 2006;32(5):849858. doi:10.1016/j.jcrs.2006.02.006

72. Ding L, Knox WH, Bühren J, Nagy LJ, Huxlin KR. Intratissue refractive index shaping (IRIS) of the cornea and lens using a lowpulse-energy femtosecond laser oscillator. Invest Ophthalmol Vis Sci. 2008;49(12):5332-5339. doi:10.1167/iovs.08-1921

73. Xu X, Zhu MM, Zou HD. Refractive versus diffractive multifocal intraocular lenses in cataract surgery: a meta-analysis of randomized controlled trials. J Refract Surg. 2014;30(9):634-644. doi:10.3928/ 1081597x-20140814-04

74. Charman WN. The eye in focus: accommodation and presbyopia. Clin Exp Optomet. 2008;91:207-225. doi:10.1111/j.14440938.2008.00256.x
Clinical Ophthalmology

\section{Publish your work in this journal}

Clinical Ophthalmology is an international, peer-reviewed journal covering all subspecialties within ophthalmology. Key topics include: Optometry; Visual science; Pharmacology and drug therapy in eye diseases; Basic Sciences; Primary and Secondary eye care; Patient Safety and Quality of Care Improvements. This journal is indexed on PubMed
Dovepress

Central and CAS, and is the official journal of The Society of Clinical Ophthalmology (SCO). The manuscript management system is completely online and includes a very quick and fair peer-review system, which is all easy to use. Visit http://www.dovepress.com/ testimonials.php to read real quotes from published authors. 